\title{
Acidification and dissolution in marine sediments of bays
}

\section{Introduction}

Besides sea level rise, climate change main consequences are ocean warming and its evil twin acidification. Ocean acidification has been identified as 'a future global climate change impact concern' because it has been slowly affecting entire ecosystems, and it is a threat to local economies, especially shellfish and fisheries productions. The scientific community has limited understanding of ocean acidification impacts, yet local and other researchers continue to monitor and evaluate them in many parts of the world. Marine bay environments are some of the richest and most biodiverse areas in the world. Ocean current circulation and upwelling of deep cold waters brings nutrient rich waters to the surface at certain times of the year, increasing productivity. Bays act as a carbon sink. Global oceans absorb twenty-five percent of our carbon dioxide emissions. So, when there is an excess of carbon dioxide emissions in the atmosphere, this excess is absorbed in seawater and marine sediment interstitial water, and a series of chemical reactions lowers $\mathrm{pH}$ increasing ocean acidity. These "ocean acidification" changes have serious implications for our coastal ecosystems, altering marine life behavior and development yet this question remains addressed. Increased acidity interferes with the process by which calcifying organisms such as crab, oysters, mussels, and certain plankton and benthic Foraminifera build their shells. Foraminifera are the base of the ocean food chain as first consumers in the ocean. If anything adverse happens to them, the entire ecological chain suffers and declines. Because ancient Foraminifera shells are microfossils and their ecological dynamics remain well preserved in ocean sediments and continental sedimentary rocks for over millions of years, their fossilized shells evidence the environmental conditions when the organism was alive. They are therefore called "Environmental Indicators" because they allow the study of the ecological and oceanographic conditions of the present and past oceans. They act like clocks, since foraminifera can be used to evidence the age of sediments and rocks that contain them. They are used as thermometers, because their shell chemistry is used to reconstruct the climate history of the ocean, and they are then indicators of sea level rise, because this condition alters environmental properties in the interface sediment-water and Foraminiferal communities respond precisely to it. This is possible since each species thrives in a particular environment having a range of preferable seawater conditions (nutrient and oxygen content, temperature, water depth, water mass, ocean currents). When the ecological chain is compromised on this level, other species like crab, mussels, rockfish and entire fisheries community that play a big role in the coastal economy are also in danger. The projection of $30 \%$ economic revenue loss in the next 50 years due to ocean acidification is an important issue of singularly merit alone to motivate funded research on this subject. Unfortunately, nowadays bays are usually regions impacted by chronic and acute environmental stress caused by anthropogenic influence, such as domestic sewage, oil and gasoline leaks, erosion, and among many other factors. These organic matter influence values are also high in the sediments, suggesting that embayment is strongly affected by organic pollution. This is particularly true for bays where, over the last century, have suffered severe environmental degradation
Volume 9 Issue 2 - 2020

\author{
Patricia Pinheiro Beck Eichler, ${ }^{1,2}$ Christofer \\ Paul Barker ${ }^{2}$ \\ 'Geodynamics and Geophysical Laboratories of Federal \\ University of Rio Grande do Norte, Brazil \\ ${ }^{2}$ Ecologic Project, USA
}

Correspondence: Patricia Pinheiro Beck Eichler, Geodynamics and Geophysical Laboratories of Federal University of Rio Grande do Norte, Brazil, Email patriciaeichler@gmail.com

Received: March 16, 2020 | Published: April 15, 2020

with no measures having been taken to prevent it. In marine sediments of polluted bays, high organic matter is acidic, with low oxygen and $\mathrm{pH}$. This condition favors Foraminiferal agglutinated tests rather than calcareous ones. Hypoxia does not appear to be a limiting factor for some Foraminiferal opportunists species that live in the upper most one centimeter of sediment ${ }^{1}$ so oxygen-depleted conditions deeper within the sediment should not have a dramatic impact on the abundance of low oxygen tolerant species. These assemblages are associated with high input of anthropogenic organic matter. Studies suggest that an opportunistic estuarine agglutinated Foraminiferal species Trochamminahadai $\mathrm{Uchio}^{2}$ increases in abundance in regions of eutrophication, such as Osaka Bay, Japan ${ }^{3-5}$ and Gamak Bay, South Korea, ${ }^{6}$ and their abundance positively correlated with the percentages of organic matter, nitrogen, and carbon and sulfur ratio in abalone (mollusk) farming area in the inner bay of Wando, South Korea. ${ }^{7}$

Environmental conditions in the interface sediment-water of marine sediments in Bays, with extremely high percentage of total organic carbon and high acidity in some areas, are likely tolerated better by an agglutinated Foraminifera species, T. hadai, than by other calcareous benthic Foraminiferal species, thereby enhancing its chances of proliferating. The other calcium carbonate benthic Foraminifera endemic fauna is dissolved by acidity in the sediment. When dissolution takes place there is a possibility of the establishment of opportunistic - not dissolvable Foraminifera fauna. Agglutinated opportunist species are made of small sediment grains and therefore are not subject to acidification. They do not make their own calcium carbonate shells, instead they look for different or same size grains, depending if they are selective or not. Figure 1 shows two different shell composition. Figure 1a presents T. hadai and 1b shows Elphidium excavatum shell.

We are still unsure what effect the invasion of the agglutinated species have on the biodiversity of native fauna in Bays. Documentation is worthwhile to show the spread of this invasive microorganism and the impact of its introduction on the local food chain, is also of interest. T. hadai probably arrived in the bay due to the active commercial fishing and recreational boating traffic, but we still have to understand what other mechanisms are responsible for 
its introduction, and in what other bays has this species has invaded. Also which of those were potential sources for ecological chain acidification should be further investigated. Usually bays closest to large cities are subjects of many identified and non identified sources having the collateral effect of eutrophication and acidification.

São Paulo State (Brazil), a severely organically-enriched benthic eutrophicated bay environment has been invaded by this opportunistic species $T$. hadai. The invasion described by Eichler et al. ${ }^{2}$ occurred sometime before 2010 and by 2014-2015, this species became one of the most dominant faunal constituents throughout the bay. The arrival of T. hadai coincides with sharp reduction in the abundance of Elphidium excavatum. Further studies are planned to investigate how this fauna replacement will be reflected in the ecological chain.

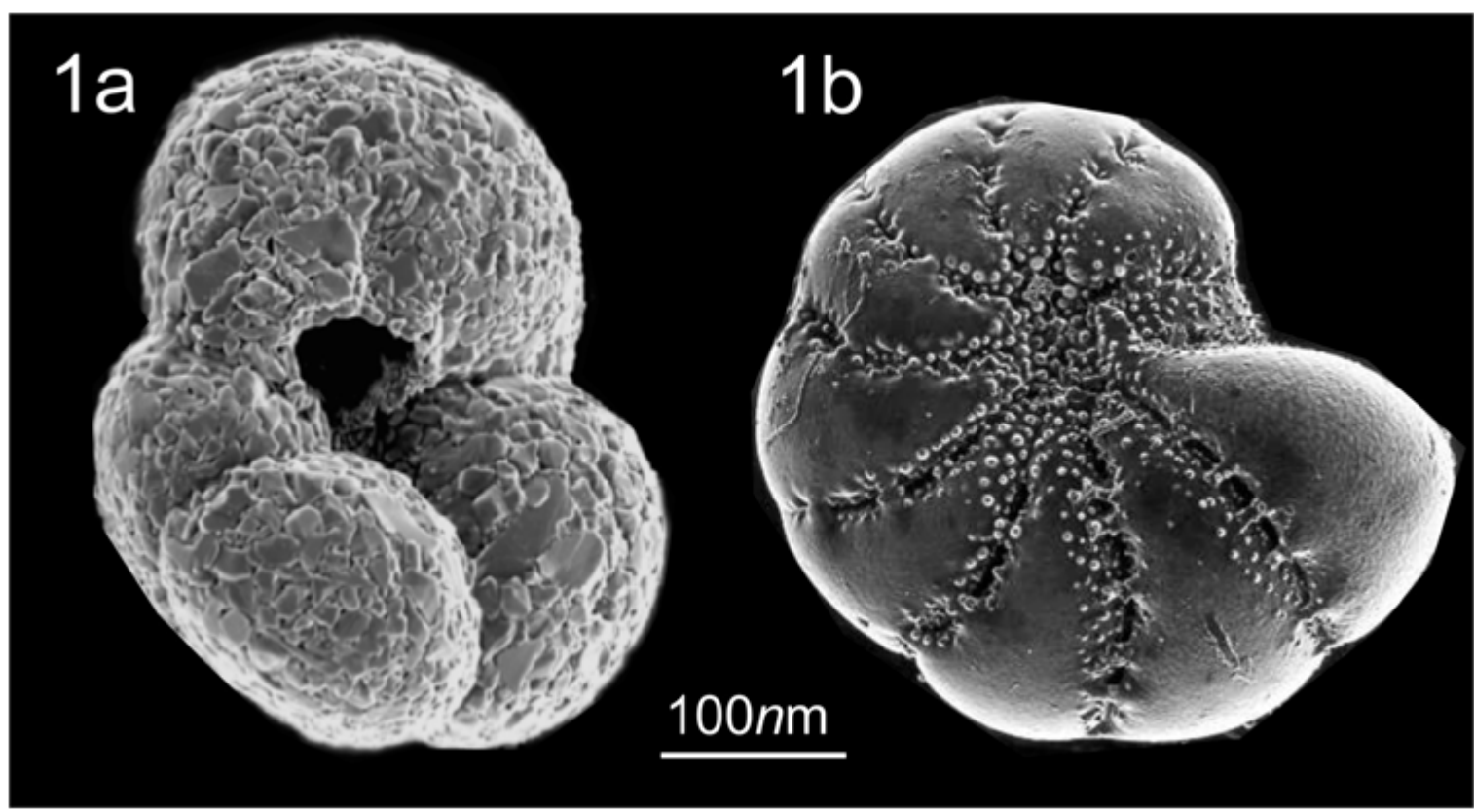

Figure I Two different shell composition. Figure Ia presents T. hadai and Ib shows Elphidium excavatum.

T. hadai was first identified as an invasive species from Japan in estuarine bottom sediments of SF Bay (San Francisco Bay), California, United States, in $1995 .{ }^{8}$ Later it was found that the species first appeared in that estuary in 1983 , comprising a mere $1.5 \%$ of the fauna, ${ }^{9}$ and by 2000 the species had been found in $96 \%$ of the samples collected from brackish and marine waters within the bay. ${ }^{10,11}$ The proliferation of $T$. hadai in SF Bay is associated with a decline in relative abundance of the common native Foraminifera calcareous $E$. excavatum. Because no sedimentological or environmental changes have occurred since T. hadai's arrival in the early 1980s, the decrease in abundance of the E. excavatum population suggests the arrival and proliferation of the invasive species in SF Bay has influenced the ecological dynamics of the native Foraminiferal fauna because its fauna replacement.

\section{Conflits of interest}

The author declares that there is no conflicts of interest.

\section{Acknowledgments}

The field and laboratory work was financially supported by the Fundação de Amparo à Pesquisa do Estado de São Paulo, Brazil (FAPESP Proc. 99/10678-5, Proc. 96/4191-8, Proc. 98/05409-2) and the Oceanographic Institute of São Paulo University (IOUSP), Brazil. Special thanks are due to the crewmembers of Véliger Oceanographic Vessel for help with the fieldwork. This research would not have been possible without the funding by the project Ciências do Mar II, Brazil
23038.004320/2014-11 (CAPES), with a post-doctoral fellowship for P.P.B.Eichler at Moss Landing Marine Laboratories, San Jose State University (MLML/SJSU) and the University of California at Santa Cruz (UCSC).

\section{Funding}

My research project was partially or fully sponsored by (Ecologic Project) with grant number (ELP:001-2020).

\section{References}

1. Matsushita S, Kitazato H. Seasonality in the benthic foraminiferal community and the life history of Trochammina hadai Uchio in Hamana Lake, Japan. In: Hemleben C, Kaminski MA, editors. Paleoecology, Biostratigraphy, Paleoceanography and Taxonomy of Agglutinated Foraminifera. NATOAS. Series, Kluwer Academic Publishers, Dordrecht. 1990;695-715.

2. Eichler PP, Mcgann M, Rodrigues AR, et al. The occurrence of the invasive foraminifera Trochammina hadai Uchio in Flamengo Inlet, Ubatuba, São Paulo State, Brazil. Micropaleontology. 2018;64(56):391-402

3. Tsujimoto A, Nomura R, Yasuhara M, et al. Benthic foraminiferal assemblages in Osaka Bay, southwestern Japan: faunal changes over the last 50 years. Paleontological Research. 2006;10(2):141-161.

4. Tsujimoto A, Nomura R, Yasuhara M, et al. Impact of eutrophication on shallow marine benthic foraminifers over the last 150 years in Osaka Bay, Japan. Marine Micropaleontology. 2006;60:258-268. 
5. Tsujimoto A, Yasuhara M, Nomura R, et al. Development of modern benthic ecosystems in eutrophic coastal oceans: The foraminiferal record over the last 200 years, Osaka Bay, Japan. Marine Micropaleontology. 2008;69(2): 225-239.

6. Lee YG, Jeong DU, Kang SR, et al. The formation of hypoxia sedimentand benthic foraminiferal change in Gamak Bay, southern coast of Korea. Ocean Polar Research. 2012;34,

7. Lee YG, Choi YH, Jeong DU. Effect of abalone farming on seawater movement and benthic foraminiferal assemblage of Zostera marina in the inner bay of Wando, South Korea. Marine Pollution Bulletin. 2016.109(1):205-220.

8. Mcgann M, And Sloan D. Recent introduction of the foraminifer Trochammina hadai Uchiointo San Francisco Bay, California, USA. Marine Micropaleontology. 1996;28(1):1-3.
9. Mcgann M, Sloan D, Cohen AN. Invasion by a Japanese marine microorganism in western North America. Hydrobiologia. 2000;421: 25-30.

10. Mcgann M, Earliest record of the invasive Foraminifera Trochammina hadai in San Francisco Bay, California, USA. Marine Biodiversity Records. 2014;7(94):1-7.

11. Benthic foraminifers in the Regional Monitoring Program's San Francisco Estuary samples. In: 1997 Annual Report for the Regional Monitoring Program for Trace Substances in the San Francisco Estuary, San Francisco Estuary Institute, Richmond, CA. 1999;249-258. 